\title{
Auto-avaliação de \\ centros de pós-graduação: \\ uma proposta em ação
}

Nívea Maria Fraga Rocha

\section{Resumo}

A pesquisa Auto-Avaliação de Centros de Pós-Graduação, surgiu como instrumento de qualidade da Fundação Visconde de Cairu (FVC). Os objetivos visavam a elaborar proposta de Auto-Avaliação para o Centro de Pós-Graduação da Fundação Visconde de Cairu (CE$\mathrm{PPEV} / \mathrm{FVC}$ ), que atendesse às exigências do contexto, características da FVC e possibilitasse a participação da comunidade acadêmica. A metodologia de pesquisa utilizada foi a pesquisa-ação, através de oficinas. Esse processo possibilitou construir coletivamente o diagnóstico institucional, identificar forças que facilitam e dificultam o processo educacional, demonstrar a qualidade do que se produz e utilizar os resultados no planejamento e tomada de decisões, para corrigir rumos e alcançar excelência institucional. A Auto-Avaliação do CEPPEV/FVC, sustentada por princípios democráticos, consolida sua responsabilidade social e compromisso científicocultural.
Palavras-chave: Avaliação institucional. Educação superior. Pós-graduação.

Abstract

Post-graduation Selfevaluation Centers: an action proposal

The research on Selfevaluation Postgraduation Centers was thought as a quality instrument of the Foundation Visconde de Cairu (FVC). The goals aimed elaborating a Selfevaluation proposal for the Postgraduation Center of that Foundation were in order to meet the context requirements, its characteristics and also to enable community academic participation. The methodology used was a research through workshops. This process allowed to build up not only an institutional diagnosis collectivelly, but also to identify forces that facilitate and/or complicate the 
educational process. It also demonstrates the quality of what was produced and how to use findings in the planning and the decisions making process to reach institutional excellence. The Self-evaluation Center of the Foundation Visconde de Cairu is based on democratic principles and consolidates its social responsibility and its scientific-cultural commitment.

Keywords: Institutional evaluation. Higher education. Post-graduation.

\section{Resumen}

\section{Auto-evaluación de} centros de postgrado: una propuesta en acción

La investigación Auto-Evaluación de Centros de Postrado, surgió como instrumento de calidad de la Fundación Vizconde de Cairu (FVC). Los objetivos visaban elaborar propuesta de Auto-Evaluación para el Centro de Postrado de la Fundación Vizconde de Cairu (CEPPEV/FVC), que atendiera a las exigencias del contexto, características de la FVC y posibilitara la participación de la comunidad académica. La metodología de investigación utilizada fue la investigación-acción, a través de talleres. Ese proceso posibilitó construir colectivamente el diagnóstico institucional, identificar fuerzas que facilitan y dificultan el proceso educacional, de mostrar la calidad de lo que se produce y utilizar los resultados en el planteamiento $y$ tomada de decisiones, para corregir rumbos y alcanzar excelencia institucional. La Auto-Evaluación del CEPPEV/FVC, sostenida por principios democráticos, consolida su responsabilidad social y compromiso científico-cultural.

Palabras clave: Evaluación institucional. Educación superior. Postgrado.

\section{Introdução \\ Origem e definição do problema}

A expansão da Educação Superior, especialmente dos Cursos de Pós-Graduação oferecidos pelas Instituições Públicas e Privadas, decorre da necessidade de superar deficiências e exigências mínimas legais de qualificação profissional, de formação da massa crítica necessária à melhoria da qualidade do Ensino e valorização da Pesquisa. Em conseqüência, intensificou-se o interesse pela reflexão crítica sobre a avaliação dos programas de pós-graduação, que vem acontecendo há muito tempo, desde que a Fundação de Aperfeiçoamento do Ensino Superior (CAPES) institucionalizou o processo sistemático e permanente de avaliação, em 1976. Entretanto o modelo utilizado nesses quase trinta anos, segundo Masetto (2004, p. 8):

[...] sobrevalorizou e privilegiou coleta de dados e informações quantitativas sobre tópicos definidos pelo seu comitê central [...] Essa medida trouxe como conseqüência a dedicação de todos os programas de pósgraduação no Brasil, durante todos esses anos, a quase que exclusivamente compreender, discutir e analisar exaustivamente os múltiplos, controvertidos, sempre modificados e complexificados critérios de avaliação da CAPES. 
Nessa trajetória, a avaliação está estabelecida nos Centros de Pós-graduação, em termos de aceitação, pela importância desse processo para o desenvolvimento das Instituições de Ensino Superior (IES) públicas e privadas. Diversificadas propostas estão sendo desenvolvidas, mas ainda é bem recente a sistemática do processo de auto-avaliação de Centros de Pós-graduação, que pode trazer significativo crescimento e dinamismo aos programas, além de ser instrumento inigualável de gestão educacional. Isto porque o autoconhecimento sinaliza acertos e equívocos, assim como facilita o (re)planejamento institucional, comprometido com o Desenvolvimento Humano e Social.

A Auto-Avaliação de Centros de PósGraduação implica pensar a IES como uma unidade que se constrói no interrelacionamento e/ou indissociabilidade das atividades que desenvolve, de Ensino, de Pesquisa, de Extensão e de Gestão Administrativa.

O contínuo aperfeiçoamento da PósGraduação é creditado principalmente à avaliação, considerada referencial de qualidade de Cursos e Programas, indicador para investimentos e ações de fomento das agências financiadoras, base para obtenção de bolsas e auxílios ou reconhecimento de cursos e validade nacional para diplomas e certificados.

processo gerencial lida, cada vez mais, com contextos desafiadores e que trazem indecisões e incertezas às organizações. Deste modo, a pesquisa pretende desenvolver estudos nessa área, envolvendo desde a concepção de avalia- ção, valores e princípios que a norteiam, à formulação de modelo e instrumentos que possam aumentar as possibilidades de acertos na tomada das decisões gerenciais e atingir a excelência da organização objeto de estudo.

Para atender às demandas do sistema educacional, da sociedade e do setor produtivo, propõe-se a Auto-Avaliação de Centros de Pós-Graduação, como instrumento de autoconhecimento e elevação dos níveis de qualidade e desempenho institucional, buscando identificar talentos, valorizar e potencializar oportunidades e decidir por manter ou mudar as ações institucionais.

Deseja-se fortalecer o caráter formativo e pedagógico da auto-avaliação, como instrumento da gestão acadêmica e administrativa, em busca de subsídios para a elevação da qualidade e relevância social da instituição, frente à sua missão científica e social (BELLONI, 2000). Pretende-se também enfatizar a utilização construtiva de seus resultados, transformando-os em prioridades, para que se promova a contínua melhoria da qualidade e do desempenho dos programas, tendo em vista a realidade institucional e suas vocações acadêmicas. Dessa forma, pretende-se facilitar o aperfeiçoamento, tanto de pessoal (docentes, discentes, corpo técnico-administrativo), quanto institucional, pelo fato de colocar a comunidade acadêmica em um processo de reflexão e autoconsciência permanente, em busca do autodiagnóstico institucional.

Partiu-se, então, da seguinte indagação:

- que modelo teórico-metodológico 
de Auto-avaliação Institucional será mais adequado para que o Centro de Pós-Graduação e Pesquisa Visconde de Cairu (CEPPEV), possa tomar conhecimento de sua real situação, atender às exigências legais e da sociedade e caminhar rumo à melhoria acadêmica e Institucional?

Para tratar o problema em foco, a pesquisa realizada apresentou como objetivos:

- analisar diversas experiências nacionais de Auto-avaliação de Centros de Pós-Graduação, articulando Ensino, Pesquisa e Extensão, para possibilitar uma visão mais abrangente dos diferentes métodos e processos avaliativos, abrir novas perspectivas para discussão, diante da diversificada realidade e permitir maior consistência teórica nesse campo;

- elaborar proposta de Auto-avaliação para o CEPPEV, que atenda às exigências legais e da sociedade, às necessidades e características da FVC e possibilite a participação dos agentes da comunidade acadêmica, como sujeitos; e

- implantar a Auto-avaliação no CEPPEV, sustentada por princípios democráticos, em caráter permanente, que consolidem a responsabilidade social e o compromisso científico-cultural.

Neste artigo, pretende-se apresentar um relato de caso de pesquisa-ação e as lições conceituais e instrumentais desenvolvidas através de oficinas vivenciais no Centro de Pós-graduação e Pesquisa Visconde de Cairu (CEPPEV).

\section{Proposta de auto-avaliação \\ Fundamentação teórica}

Para possibilitar maior dinamismo e crescimento à Pós-Graduação, atender às demandas do sistema educacional, da sociedade e do setor produtivo, a Fundação Visconde de Cairu, através do Centro de Pós-Graduação e Pesquisa Visconde de Cairu (CEPPEV), vem desenvolvendo sua auto-avaliação, como instrumento de elevação dos níveis de qualidade acadêmica, frente a sua missão científica e social.

A proposta de Auto-Avaliação de Centros de Pós-Graduação procura identificar os aspectos que dificultam e/ou facilitam sua ação acadêmica, assim como implementar estratégias de intervenção, para corrigir rumos, consolidar ou superar sua ação pedagógica e desempenhar, com melhor qualidade, sua função de produção e disseminação do conhecimento. $O$ conceito de qualidade vai além das relações de custo, benefício, eficiência e eficácia, buscando outras variáveis que permitam sinalizar o desempenho da Instituição. A qualidade é vista no inter-relacionamento de suas ações, nos resultados efetivos que produzem, quando referenciadas nos objetivos éticos, sociopolíticos e pedagógicos que a norteiam. Como diz Sordi (2002, p. 67):

Avaliar implica o desejo de conhecer, tirar a máscara, ato de entrega que não pode ser imposto simplesmente. Daí a defesa de processos de avaliação regidos pela adesão voluntária, que sinalizam na direção do compromisso com os resultados avaliativos, dando-lhes conseqüência. 
Essencialmente formativa (CRONBACH, 1963; GUBA; LINCOLN, 1990; SCRIVEN, 1967; STUFFLEBEAN, 1981) e concebida como problematização, questionamento e reflexão sobre a ação (HOFFMANN, 1993), a Auto-Avaliação vai além da coleta de informações, procurando envolver aspectos humanos, políticos, sociais, culturais e contextuais, com uma conotação não de punir, mas de promover melhorias. Como avaliação formativa, os benefícios não estão nos resultados finais, mas em seus processos de ação e em suas construções coletivas, ao longo da ação educativa, tendo lugar de destaque a participação da comunidade acadêmica. Implica pensar a IES como uma unidade que se constrói no inter-relacionamento e/ou indissociabilidade das atividades de Ensino, Pesquisa e Extensão.

Seguindo as orientações de Dias Sobrinho e Ristoff (2000, p. 106):

[...] a avaliação institucional deve procurar estabelecer uma compreensão de forma razoavelmente integrada e articulada do conjunto da universidade, através da compreensão das partes. A compreensão dos aspectos isolados deve se dar no esforço de integração desses elementos com as diversas outras dimensões constitutivas do todo.

Como as Instituições de Ensino Superior (IES) têm identidade própria, que precisa ser respeitada, cada uma deve construir seu modelo de avaliação, a partir de sua história, de seu contexto e de suas prioridades. Assim, tomando por base sua Missão, as Normas Legais e os respectivos Programas de Pós-Gradua- ção, o projeto de Auto-Avaliação do CEPPEV pretende:

- avaliar a Pós-Graduação, articulando o Ensino, a Pesquisa, a Extensão e a Gestão;

- demonstrar e subsidiar a qualidade do que produz;

- propiciar a credibilidade do que faz no contexto interno e externo;

- e utilizar os resultados da avaliação no (re)planejamento e tomada de decisão.

A proposta de Auto-Avaliação do CEPPEV defende a descentralização dos trabalhos, no sentido de ajustar a avaliação às peculiaridades de cada Programa, sem perder de vista a unidade, para possibilitar tomadas de decisão rápidas, eficientes e responsáveis. Nesse sentido, ao resgatar o cotidiano em um clima de discussão e diálogo, vem apresentando dimensões políticas e educativas, que valem tanto para o sujeito, como para o coletivo.

Os critérios gerais estabelecidos para a Auto-Avaliação do CEPPEV envolvem:

- mérito, ao analisar a qualidade e excelência das atividades dos processos/produtos;

- relevância social, ao verificar o impacto do trabalho realizado frente à ciência, à educação e à sociedade em geral;

- impacto social e avanços, ao gerar novas descobertas e mudanças significativas.

Os Programas de Pós-Graduação do CEPPEV estão sendo avaliados no próprio contexto em que são desenvolvidos, considerando principalmente suas missões, objetivos, estruturas, corpo docente e discen- 
te, corpo técnico-administrativo e infra-estrutura institucional.

Os pressupostos metodológicos da Auto-Avaliação do CEPPEV são: respeito à identidade institucional; participação; negociação; conjugação da avaliação interna e externa; flexibilidade; construção coletiva; restituição sistemática e ágil.

Os parâmetros de qualidade defendidos envolvem, entre outros aspectos:

a) atendimento às normas legais;

b) atendimento à missão institucional;

c) contribuição ao conhecimento acumulado;

d) contribuição à construção do conhecimento, articulando Ensino (Graduação e Pós-Graduação), Pesquisa e Extensão;

e) divulgação institucional;

f) abertura de novas áreas para o Ensino, a Pesquisa e a Extensão;

g) devolução social.

A proposta de Auto-Avaliação do CEPPEV está sendo desenvolvida através de uma Matriz, que serve de roteiro para o levantamento de dados e análise crítica das atividades desenvolvidas, contando ainda com o desenvolvimento do processo de meta-avaliação para avaliar a eficiência/eficácia do processo avaliativo e melhorar, cada vez mais, a dinâmica do modelo utilizado.

\section{Avaliando a pesquisa}

A Pesquisa é considerada agente impulsionador das atividades no âmbito do Ensino Superior, porque projeta um patamar de qualificação que pode facilitar o desenvolvimento pleno da ins- tituição e reafirmar sua identidade. Sua importância reside, principalmente, na contribuição para a evolução do conhecimento humano, em todos os setores, da ciência pura à aplicada, da matemática à literatura ou à tecnologia. Na Pós-Graduação, ela é desenvolvida conforme normas metodológicas consagradas pela ciência e segundo critérios rigorosos de processamento das informações.

Entre as finalidades da Educação Superior, definidas no art. 43 da Lei n. 9.394/ 96 (BRASIL, 1996), está o incentivo ao trabalho de investigação científica, visando ao desenvolvimento da ciência e da tecnologia e à criação e difusão da cultura e, desse modo, ao entendimento do homem e do meio em que vive.

A Pesquisa fornece conhecimento detalhado da realidade, fundamenta a elaboração de diretrizes da instituição, proporciona confiança e segurança para o administrador em suas ações e meIhora o atendimento das demandas do público-alvo.

A partir da importância e das necessidades Institucionais e legais de indissociabilidade entre Ensino, Pesquisa e Extensão, a proposta de Auto-Avaliação do CEPPEV contempla a avaliação das Atividades de Pesquisa realizadas por professores e alunos, de forma quantitativa/qualitativa, envolvendo a produção científica, nos últimos três (3) anos, à luz de critérios institucionais e das agências financiadoras (CAPES e CNPq). Para esse mister, estabeleceram-se requisitos mínimos obrigatórios e recomendáveis que os Programas de Pós-Graduação 
precisam satisfazer, para que tenham um perfil de excelência institucional, maior competitividade nacional e apresentem sinais evidentes de que o corpo docente e discente desempenha papel de liderança na comunidade científica.

Para alcançar o pleno desenvolvimento das metas propostas pela Fundação Visconde de Cairu, foram planejadas ações avaliativas, no sentido de fortalecer a política de acompanhamento Institucional, através dos seguintes parâmetros de qualidade:

- atendimento às exigências legais;

- contribuição ao conhecimento acumulado;

- contribuição à construção do conhecimento, articulando Ensino (Graduação/Pós-graduação), Pesquisa e Extensão;

- atendimento à missão institucional;

- divulgação da instituição;

- abertura de campo para consultoria e Extensão;

- abertura de novas áreas de pesquisa;

- solidificação do nome institucional.

Para fins de Auto-Avaliação do CEPPEV, é imprescindível listar os projetos/ linhas de pesquisas, identificando, entre outras questões:

\section{Projeto/Programa/Curso}

- período de realização;

- órgãos executores - Departamentos e Unidades envolvidas;

- órgãos financiadores (quando houver);

- clientela;

- perfil do Coordenador;

- corpo docente (qualificação, regime de trabalho, experiência acadêmica e administrativa).

\section{Execução do Projeto/ Programa/Curso}

- descrição das etapas: seleção, realização, ocorrências;

- avaliação do aproveitamento e freqüência apresentados pelos participantes, junto ao setor competente;

- despesas/receitas empreendidas e a empreender.

Para avaliar a Pesquisa, considerar-se-á, entre outros aspectos:

\section{Atividades de pesquisa}

- adequação e abrangência dos projetos de pesquisa em relação aos PP dos Cursos;

- vínculo com as linhas e projetos de pesquisa da Pós-Graduação;

- participação do corpo docente e discente nos projetos de pesquisa;

- outras informações que considere pertinentes.

\section{Corpo docente}

- produção científica permanente divulgada anualmente em periódicos indexados de circulação nacional e internacional;

- atuação do corpo docente na graduação ou em atividades equivalentes, tais como: orientação de iniciação científica, projetos de conclusão de curso, etc.;

- participação do corpo docente em comitês científicos, comissões, assessoramentos de órgãos de Pesquisa e Ensino;

- participação em corpo editorial de periódicos científicos, congressos e associações, em âmbito nacional ou internacional;

- demonstração da capacidade de captação de projetos/recursos, particularmente em casos de comprovada 
seleção em processos em âmbito nacional ou internacional;

- reconhecimento do corpo docente, pela sua contribuição à sociedade brasileira, através do desenvolvimento de projetos, programas, protótipos, patentes, etc.

A qualidade do Corpo Docente se deve, principalmente, à sua qualificação e produção científica. É importante que os docentes tenham envolvimento nas atividades de Ensino, Pesquisa e Extensão, de forma regular e com uma distribuição equilibrada das atividades.

A proposta de Auto-Avaliação do CEPPEV prevê avaliação da participação dos docentes/pesquisadores, em:

- congressos e reuniões nacionais e internacionais;

- publicação dos resultados de pesquisas em livros e revistas indexadas;

- cursos de Pós-Graduação;

- pesquisa interinstitucional;

- Comitês, Comissões e Assessoramentos em órgãos de Pesquisa, Extensão e Ensino;

- corpo editorial de periódicos científicos;

- Programas de Iniciação Científica com estudantes.

\section{Produção intelectual}

- adequação dos tipos de produção ao Projeto Pedagógico Institucional;

- vínculo aos Projetos, Linhas de Pesquisa e Áreas de Concentração;

- qualidade dos veículos ou meios de divulgação ou apresentação;

- regularidade da produção;

- autoria ou co-autoria de discentes;

- outras informações que considere pertinentes.

\section{Monografias}

- vínculo das monografias com as Áreas de Concentração e com as Linhas e Projetos de Pesquisa;

- adequação dos projetos de pesquisa ao nível dos cursos; e,

- outras informações que considere pertinentes.

No que se refere à produção científica, os docentes precisam apresentar regularidade de publicações, pelo menos duas por biênio, em forma de livros, capítulos de livros ou artigos em periódicos indexados, nacionais ou internacionais, pertinentes à área.

Compete à Comissão responsável pela Avaliação das Atividades de Pesquisa efetuar a análise do mérito dos projetos e seus desdobramentos, as condições de infraestrutura institucionais e, considerando o conjunto de informações necessárias que instruem as mesmas, emitir parecer circunstanciado sobre a situação dessas atividades frente às normas legais e institucionais, a contribuição à construção do conhecimento e à articulação do Ensino, Pesquisa, Extensão e Missão Institucional.

\section{Avaliando a extensão}

A indissociabilidade entre as atividades de Ensino, Pesquisa e Extensão é fundamental no fazer acadêmico, não só por garantir o atendimento às normas legais, como para efetivar a qualidade científica, tecnológica e artístico-cultural da Instituição de Ensino Superior. Indubitavelmente, por envolver ações interdisciplinares, contextualizadas e integradas, as atividades de Extensão não podem ser vistas fora do processo acadêmico ou divorciadas da Pesquisa e do Ensino. 
Como uma das finalidades do Ensino Superior, a Extensão universitária é considerada, continuamente, a atividade que faz a integração das IES com a comunidade, seja como prestadora de serviços, captadora de recursos financeiros, articuladora de repasses de conhecimentos técnicos, de informação de projetos e cursos, de projetos de difusão cultural e de muitas outras atividades.

\section{A Extensão é entendida como: \\ [...] prática acadêmica que interliga a Universidade nas suas atividades de ensino e de pesquisa, com as deman- das da maioria da população, possibili- ta a formação do profissional cidadão e se credencia, cada vez mais, junto à so- ciedade como espaço privilegiado de produção do conhecimento significati- vo para a superação das desigualdades sociais existentes. (BRASIL, 1999, p. 1).}

Daí porque é importante consolidar a prática da Extensão, que implica em relações multi, inter ou transdisciplinares e interprofissionais, para possibilitar constante busca do equilíbrio entre as demandas socialmente exigidas e as inovações que surgem do trabalho acadêmico.

A Extensão privilegia práticas voltadas ao atendimento de necessidades sociais emergentes, relacionadas com diversas áreas (educação, saúde, habitação, etc.), o que justifica tornar permanente sua avaliação, como um parâmetro de qualidade da própria Instituição.

As atividades de Extensão podem também possibilitar novos meios e processos de produção, inovação e transferência de conhecimentos, possibilitando a ampliação do acesso ao saber e maior desenvolvimento tecnológico e social do país, referenciando as universidades como instituições sintonizadas com a realidade social. (BRASIL, 2000).

O Decreto $n^{\circ} 3.860 / 01$ (BRASIL, 2001, p.6), que dispõe sobre a organização do Ensino Superior, determina, no capítulo IV, que trata da Avaliação, art. 17, Inciso III, Parágrafo $1^{\circ}$ :

I - a organização didático-pedagógica;

II - o corpo docente, considerando principalmente a titulação, a experiência profissional, a estrutura da carreira, a jornada de trabalho e as condições de trabalho;

III - a adequação das instalações físicas gerais e específicas e equipamentos integrados ao desenvolvimento do curso.

IV - as bibliotecas, com atenção especial para o acervo especializado, inclusive o eletrônico, para as condições de acesso às redes de comunicação e para os sistemas de informação, regime de funcionamento e modernização dos meios de atendimento.

A Lei de Diretrizes e Bases da Educação Nacional (BRASIL, 1996, p.17), no que se refere à organização da Educação Nacional, determina que a Educação Superior tem também a finalidade de "[...] promover a extensão, aberta à participação da população, visando à difusão das conquistas e benefícios resultantes da criação cultural e da pesquisa científica e tecnológica geradas na instituição".

Pelo destaque que tem sido dado ao papel social da Extensão, nos meios universitários, como ação que possi- 
bilita a interação universidade/sociedade e como elemento capaz de facilitar a relação teoria/prática, promovendo a troca entre saberes acadêmicos e populares, considera-se oportuno o momento político para se implantar o processo permanente de avaliação de suas ações, no sentido de valorizá-la e fortalecê-la.

A proposta de Auto-Avaliação do CEPPEV prevê a avaliação das atividades de Extensão, com os objetivos de:

- analisar as atividades de Extensão da Fundação Visconde de Cairu/CEPPEV visando à sua melhoria, no sentido de fornecer subsídios para um planejamento mais satisfatório dessas atividades;

- organizar as informações relevantes e conhecer com profundidade seus processos extensionistas, identificando as tendências gerais; $e$,

- subsidiar o processo decisório, no sentido das modificações necessárias, de acordo com os objetivos e metas traçados pela instituição.

Para orientar o processo de avaliação, defendem-se os seguintes princípios, citados pelo Fórum Nacional de Pró-Reitores de Extensão (BRASIL, 2000, p. 7):

- a extensão universitária é processo educativo, cultural e científico;

- a extensão universitária deve caminhar articulada com o ensino e a pesquisa;

- a extensão articula as relações entre a comunidade acadêmica e a sociedade no sentido da transformação social;

- a extensão universitária, como prática acadêmica, deve dirigir seus interes- ses às grandes questões sociais do país e àquelas demandadas pelas comunidades regionais e locais.

Esses princípios estão inter-relacionados, no sentido de atender ao compromisso da Fundação Visconde de Cairu / CEPPEV, no tocante:

- à estruturação e efetivação das atividades de Extensão;

- às ações desenvolvidas e ao impacto destas junto aos vários segmentos sociais;

- à avaliação das atividades de Extensão.

\section{A proposta de auto-avaliação do} CEPPEV pretende avaliar as atividades de Extensão, no que se refere a:

\section{Organização}

- consolidar o Sistema de Informação sobre a Extensão, através da organização de um Banco de Dados;

- verificar as linhas de Extensão previstas no Projeto Pedagógico Institucional (PPI) e no Plano de Desenvolvimento Institucional (PDI);

- organizar os indicadores quantitativos/qualitativos a serem utilizados nas atividades de Extensão;

- verificar se o Programa de Fomento à Extensão prevê recursos para custeio e bolsas.

\section{Articulação com a sociedade}

- Levantar os Projetos de Extensão desenvolvidos pela Fundação Visconde de Cairu (CEPPEV) em parceria com agências financiadoras.

É necessário listar as atividades de Extensão existentes na Fundação Visconde de Cairu, identificando, principalmente:

\section{Projeto/Curso/Atividade}

- período de realização; 
- órgãos executores - Departamentos e Unidades envolvidas;

- órgãos financiadores, quando houver;

- clientela;

- perfil do coordenador;

- corpo docente (qualificação, regime de trabalho, experiência acadêmica e administrativa);

\section{Execução do Projeto/Curso/Ativi- dade}

- descrição das etapas;

- avaliação do aproveitamento e freqüência apresentados pelos participantes;

- despesas/receitas empreendidas e a empreender.

Os indicadores, vistos como instrumentos de apoio ao processo de avaliação, vão auxiliar na coleta de informações:

\section{Indicadores selecionados a partir} desses princípios

- grau de formalização da Extensão na estrutura institucional;

- definição clara das políticas institucionais, com explicitação de metas e prioridades;

- tipologia das atividades de Extensão;

- existência de sistemas de informação sobre as atividades desenvolvidas;

- grau de participação da Extensão no orçamento da universidade;

- grau de valorização no Plano de Carreira Docente e Técnico-Administrativa;

- existência de programas institucionais de fomento às atividades de Extensão, especialmente programas de bolsas;

- grau de envolvimento dos docentes/ discentes e técnicos da instituição nas atividades de Extensão;

- grau de interação das atividades de Extensão com o Ensino e a Pesquisa;
- grau de inserção das atividades de Extensão nos programas departamentais;

- grau de abrangência disciplinar das atividades de Extensão;

- grau de participação das atividades de Extensão na produção acadêmica da instituição;

- outros.

Indicadores dos impactos sociais das atividades de Extensão

- relevância social, econômica e política dos problemas abordados nas instituições;

- segmentos sociais envolvidos;

- interação com órgãos públicos e privados e segmentos organizados;

- objetivos e resultados alcançados;

- apropriação, utilização e reprodução, pelos parceiros, do conhecimento envolvido na atividade de Extensão;

- efeito da interação resultante da ação da Extensão nas atividades acadêmicas;

- outros.

\section{Indicadores quantitativos das} ações extensionistas

- número de projetos desenvolvidos;

- público estimado/beneficiado;

- número de eventos realizados;

- tipos de cursos realizados e/ou a realizar;

- número de certificados expedidos;

- número de produtos elaborados (CD's, vídeos, filmes, cassetes, etc.);

- prestação de serviços realizadas;

- número de municípios atendidos em ações extensionistas;

- outros.

A avaliação da Extensão, articulada com a missão da Fundação Visconde de Cairu e com seu Projeto Pedagó- 
gico, está inserida na proposta de AutoAvaliação do CEPPEV. Integrada com as demais áreas do fazer acadêmico Ensino (Graduação e Pós-Graduação) e Pesquisa - a presente avaliação das atividades de Extensão passa a ser tecnicamente competente e politicamente legítima, já que envolverá, no processo, a comunidade acadêmica (coordenadores, professores, alunos e funcionários) e membros dos grupos participantes das atividades de Extensão.

\section{Pressupostos quantitativos/quali- tativos}

- verificar a quantidade versus qualidade da produção advinda da Extensão (produções acadêmicas e prestações de serviço);

- quantidade versus qualidade das ações desenvolvidas: programas, projetos, eventos, cursos;

- demonstração da credibilidade das ações de Extensão no contexto interno e externo;

- mudanças qualitativas/quantitativas implementadas no planejamento (tomada de decisão), nas áreas de Ensino, Extensão e Pesquisa, a partir dos resultados das ações.

impacto social das atividades de Extensão será avaliado pelos indicadores:

- relevância social, econômica e política dos problemas abordados nas atividades;

- caracterização e qualificação dos segmentos sociais envolvidos nas atividades;

- grau de interação com órgãos públicos e privados e segmentos organizados da sociedade civil;

- objetivos, resultados alcançados e repercussão das atividades de Exten- são, tais como a construção conjunta de novo conhecimento;

- apropriação, utilização e reprodução do conhecimento envolvido na atividade de Extensão pelos parceiros;

- efeito nas atividades acadêmicas da interação social resultante das atividades;

- níveis de transformação dos indicadores sociais resultantes das atividades.

\section{Dimensões da avaliação}

- política institucional: no que se refere à Extensão;

- infra-estrutura: reais condições físicas e gerenciais de realização da Extensão e possibilidades de se consolidarem as metas almejadas;

- relação faculdade-sociedade: atividades de Extensão articuladas com a sociedade, no sentido de transformações recíprocas;

- planejamento estratégico de Extensão: possibilidades de incorporação da Extensão na vida acadêmi$c a$, valorizando as experiências desenvolvidas pelo conjunto de participantes (professores, funcionários e alunos);

- produção acadêmica: resultante da ação da Extensão, que elabore e dissemine conhecimentos no âmbito universitário.

A Auto-Avaliação do CEPPEV não tem propósitos de controle e fiscalização, no sentido de punição, mas no sentido de buscar subsídios que permitam favorecer tomada de decisões e introduzir novas alternativas de ação. Pretende-se, principalmente, avaliar metas e resultados alcançados, que possam ajudar a melhorar o processo acadêmico. 
Espera-se que o Projeto de AutoAvaliação do CEPPEV - biênio 2004 2005 - traga o debate sobre a missão da instituição, frente a seu papel na reconstrução do espaço social, sobre suas necessidades e prioridades e possibilite a ampliação da percepção e análise das atuais práticas de Ensino (Graduação e Pós-Graduação), Pesquisa e Extensão desenvolvidas na Fundação Visconde de Cairu.

\section{Auto-avaliação em ação}

Para implantar a auto-avaliação do CEPPEV, em caráter permanente, sustentada por princípios democráticos que consolidassem sua responsabilidade social e compromisso científico-cultural, foi necessário sensibilizar gestores, professores, alunos e funcionários. Através das oficinas de auto-avaliação, foi possível construir coletivamente uma visão diagnóstica dos programas de Pós-Graduação, em dez dimensões, identificando forças que contribuíam para facilitar e/ou dificultar seu processo educacional.

O processo de Auto-avaliação do CEPPEV foi implantado, em caráter experimental, por um período de dois anos (2004-2005). A auto-avaliação considerou, principalmente, os objetivos, estrutura, corpo docente, discente e técnicoadministrativo envolvidos nas atividades de Ensino, Pesquisa e Extensão, e a infra-estrutura oferecida para o funcionamento da Pós-Graduação.

Os grupos de professores, alunos e técnico-administrativos se reuniram, de início, por setores. Na seqüência, esses grupos buscaram apoio na discussão com outros grupos e/ou outros setores e, no final, analisaram as situações em grandes grupos. Houve representatividade na participação de docentes dos três Programas de Mestrado existentes no CEPPEV/FVC.

Contou-se com a disposição, responsabilidade e vontade de contribuir com a proposta de auto-avaliação da totalidade dos técnico-administrativos presentes. Por fim, com a participação da comunidade acadêmica - professores, alunos e funcionários -, foi possível detectar muitos aspectos positivos do Centro de Pós-Graduação, que precisam ser reforçados, e fraquezas institucionais que estão a exigir soluções urgentes a curto, médio e longo prazo.

O processo de Auto-Avaliação do CEPPEV foi realizado em três momentos interrelacionados:

\section{Momento I: eu e o centro de pós-graduação}

No primeiro momento, convidou-se a comunidade acadêmica para realizar uma introspecção e tentar identificar seus sentimentos, em relação ao Centro de Pós-Graduação. Foi entregue uma foIha de ofício dobrada, com duas folhas autocolantes de cores diferenciadas, para que registrassem dois (2) sentimentos que facilitavam o desenvolvimento de suas atividades profissionais/acadêmicas, e dois (2) sentimentos que dificultavam este mesmo processo.

O levantamento dos dados, nesse primeiro momento, foi por segmento: professores de cada Programa/Curso, alunos/Programa/Curso/turma e técnico- 
administrativos. Pretendeu-se fazer um levantamento inicial do nível de satisfação com o Centro de Pós-graduação, através dos sentimentos que facilitavam e/ou dificultavam a ação acadêmica nessa instituição, nos Cursos de Mestrado e nos diversos setores existentes.

Verificou-se que o nível de satisfação da comunidade acadêmica era alto. Os sentimentos que mais apareceram e que facilitavam a tarefa do dia-a-dia, nesse primeiro momento, foram:

a) excelente clima institucional;

b) inter-relacionamento da comunidade acadêmica;

c) bom relacionamento humano da administração com professores, alunos e funcionários;

d) existência de clima de união e a amizade;

e) agilidade para sanar as dificuldades e/ou problemas;

f) gostar do que faz; e,

g) ter uma equipe de profissionais competentes.

Foram apontados também sentimentos que dificultavam a ação acadêmica no diaa-dia. Entre eles, foram mais citados:

a) carência e falta de agilidade na comunicação entre os setores;

b) ausência de reuniões periódicas para discussão, atualização e informações acadêmicas;

c) quadros de aviso desatualizados;

d) dificuldade de fornecimento de material para o trabalho;

e) deficiência no suprimento de material para trabalhar, principalmente de fardas; e,

f) falta na biblioteca, de livros adotados pelos professores.

\section{Momento II: diagnóstico dos pro- gramas de mestrado}

O Momento II envolveu a construção de uma visão diagnóstica dos Programas de Mestrado existentes no Centro de Pós-graduação, a partir do preenchimento de três quadros. No quadro 1, solicitava-se dos professores, alunos e técnico-administrativos que apontassem as variáveis facilitadoras da realização do processo acadêmico/profissional, a partir das dez dimensões dadas como pistas, que tivessem relação com seu fazer do dia-a-dia. No quadro 2 , solicitava-se que a comunidade apontasse variáveis dificultadoras do processo acadêmico/profissional e, paralelamente, sugerisse propostas de ações para solucioná-las. E, para encerrar o processo, no quadro 3, solicitava-se um parecer dos vários segmentos sobre o processo de auto-avaliação coletiva - meta-avaliação - para meIhoria do processo de auto-avaliação desencadeado naquele momento.

Pretendia-se possibilitar à comunidade acadêmica a construção coletiva de uma visão diagnóstica do Centro de Pós-Graduação, dos Programas/Cursos e Setores Administrativos, e a identificação das forças que contribuem para facilitar e/ou dificultar o processo educacional do CEPPEV. Além disso, precisava-se ter clareza para propor alternativas de superação a curto, médio e longo prazo, estabelecer estratégias de intervenção, para corrigir rumos, consolidar ou superar sua ação pedagógica, para alcançar, efetivamente, maior qualidade institucional.

A valorização do nível de participação de professores, alunos e funcionários foi 
importante, porque são eles os sujeitos que melhor conhecem a realidade a ser avaliada e, com segurança, os mais interessados em melhorá-la.

O compromisso principal da proposta de Auto-Avaliação do CEPPEV era possibilitar que professores, funcionários e alunos, de forma cooperativa, refletissem sobre seu dia-a-dia e descrevessem os aspectos positivos, os aspectos frágeis da IES e gerassem suas próprias alternativas de ação. Foi um processo de autocrítica, em que avaliador e avaliado foram as mesmas pessoas, o que possibilitou tomada de decisões mais adequadas e eficazes, por parte da comunidade envolvida, como também dos gestores institucionais.

Apresentam-se, a seguir, as dez dimensões colocadas à disposição da comunidade acadêmica, para facilitar o processo de auto-avaliação:

- Planejamento do curso (Projeto Pedagógico);

- Corpo docente (de cada curso);

- Corpo técnico-administrativo (do curso e geral);

- Auto-avaliação do aluno;

- Coordenação de curso;

- Coordenação do CEPPEV;

- Infra-estrutura física e tecnológica;

- Responsabilidade social da FVC/CEPPEV;

- Relação entre a FVC/CEPPEV e a sociedade: formas de comunicação;

- Políticas de atendimento aos discentes.

Essas dimensões foram oferecidas como pistas para a auto-avaliação dos vários segmentos. Professores, técnico- administrativos, alunos e gestores deveriam, a partir da reflexão individual e/ ou coletiva dessas ou de três outras dimensões que o grupo considerasse mais pertinentes, fazer o preenchimento dos três quadros.

Deu-se total autonomia aos grupos/ setores para avaliarem as dimensões que considerassem mais pertinentes e/ou próximas, além de poderem acrescentar outras que julgassem convenientes. Tiveram autonomia também para desenvolver a auto-avaliação em pequenos grupos ou no "grupão", desde que escoIhessem, entre os presentes, um ou dois moderadores, para facilitar a construção coletiva da proposta de ação e garantir a participação de todos, opinando, analisando e acrescentando.

Cada segmento, por curso, recebeu um ou mais conjuntos (kits), contendo os seguintes materiais:

- programação da atividade;

- três quadros (Quadro 1, Quadro 2 e Quadro 3) para registro das variáveis solicitadas;

- 10 dimensões em análise, como pistas para a auto-avaliação;

- Projeto Pedagógico de cada Curso de Mestrado;

- outros documentos solicitados.

Os Quadros 1, 2 e 3 estavam disponíveis em todos os micros, para facilitar o preenchimento pelos diversos segmentos. Estes tinham apenas que fazer a identificação do curso, segmento e setor, para manter o sigilo e anonimato dos participantes. Foram mantidas listas de freqüência dos participantes, em cada sala ou setor. 


\section{Momento III: integração das auto-avaliações}

Os vários segmentos (coordenadores, professores, alunos e técnico-administrativos) discutiram em grupo, para fazer a integração das atividades realizadas em alguns momentos em separado e construir o diagnóstico de cada situação. Alguns resolveram, desde o início, fazer a auto-avaliação de forma coletiva. Além disso, foi solicitado que cada segmento fizesse uma análise geral, a título de conclusão.

A comunidade acadêmica desenvolveu o processo de auto-avaliação do CEPPEV em seus próprios espaços de trabalho. Os alunos participaram do processo nas salas de aula, indicadas para cada curso, possuindo o mesmo material explicitado anteriormente.

Percebeu-se que faltou, em alguns cursos, leitura mais aprofundada do Roteiro de Auto-Avaliação. Ao não terem clareza do processo, apesar do grande empenho de todos em realizar a atividade proposta, houve equívocos com relação à metodologia de auto-avaliação utilizada, confundindo-se os dados descritivos solicitados nos Quadros 1 (variáveis que facilitam a realização do processo acadêmico/profissional) e no Quadro 2 (variáveis que dificultam o processo acadêmico/profissional), com mensuração quantitativa, através de conceitos, além da análise, a partir das dez dimensões colocadas como pistas, para a Auto-Avaliação.

Roteiro de Auto-Avaliação do CEPPEV (2004) foi apresentado e discutido em reunião, na presença dos gestores, Coordenadores dos Cursos de Mestrado, pro- fessores e representantes estudantis. Nesse roteiro, destaca-se:

Os vários segmentos terão total autonomia para avaliarem as dimensões que considerarem mais pertinentes e/ou próximas, além de poderem acrescentar outras(s), se julgarem convenientes [...] Todas as pessoas do setor e/ou grupo deverão participar opinando, analisando, acrescentando. (CEPPEV, 2004, p. 2).

Apesar do número limitado de alunos e professores em um dos Programas/ Cursos de Mestrado, os depoimentos baseados na análise das experiências do cotidiano de cada curso, numa perspectiva crítica, foram bastante enriquecedores, possibilitando não só a construção de um diagnóstico do CEPPEV, como a elaboração de proposta coletiva de ação, para os problemas detectados pelos vários segmentos.

As falas a seguir, de professores, alunos e funcionários, são representativas da meta-avaliação:

"Esta auto-avaliação é muito importante para o crescimento da instituição, pois apresenta a visão dos gestores, dos funcionários, professores e alunos. Esta análise criteriosa, feita nesse momento, ajudará a encontrar soluções adequadas a cada dimensão, melhorando os serviços."

"Pela importância do processo e responsabilidade de todos com a análise a ser feita, necessitaria de maior tempo." "Achamos muito importante, pois só assim poderemos detectar as dificuldades encontradas no nosso setor e fazer com que a instituição se desenvolva mais." "A proposta da avaliação foi extremamente válida. A forma como ela foi rea- 
lizada, nem tanto."

"Essa avaliação pode vir a ser uma excelente "ferramenta" de balizamento para a coordenação dos Programas. Através dela será possível sentir as carências, assim como os pontos positivos do curso, na visão dos alunos e professores, facilitando o processo de tomada de decisões que fortaleçam os cursos de mestrado."

"A avaliação poderia ser em forma de questionário, disponibilizado via web, que garantiria mais comodidade a todos que dela participaram."

"A programação das atividades da autoavaliação deveria ser divulgada com mais antecedência, para maior participação." "A ferramenta utilizada para a avaliação (WORD) não é adequada, poderia ser utilizado um fórum na Internet para a comunidade do CEPPEV construir a avaliação à distância."

"Valeu a pena. Apesar de uma certa resistência inicial, característica da natureza humana a mudanças, a auto-avaliação dos Programas de Pós-Graduação é essencial. Acho, entretanto, que podemos, nos vindouros, dispor de mais tempo. Acho também que coordenadores e professores do curso, que devem estar "vestindo a camisa", envolvidos com o curso, devam parar para pensar no curso, no projeto pedagógico, com muita freqüência."

"Mais uma vez é de se bater palmas para a iniciativa. Corporativismo deve ser deixado de lado em prol da melhoria da capacidade de ensino do professor. A avaliação externa também se faz necessária." "Minha meta-avaliação final é que o processo foi regular. Sem embargo, a idéia e a iniciativa são de alta relevância."
A investigação não tratou simplesmente de conhecer a realidade acadêmica em suas distintas dimensões, mas também levantar categorias de análise com a participação da comunidade acadêmica (professores, funcionários e alunos) para posterior avaliação online, assim como estabelecer estratégias de ação, para promover a melhoria da qualidade institucional em curto, médio e longo prazo.

Sabe-se que o papel da auto-avaliação é estabelecer as prioridades, objetivos, medidas e meios necessários, para que o processo de autoconhecimento possibilite o desvendamento de potencialidades e dificuldades, nas diversas instâncias organizacionais que constituem a Instituição de Ensino Superior. Dessa forma, transforma-se em um momento crucial de comunicação, transparência, exposição pública e prestação de contas à sociedade, ao tempo em que fortalece o desenvolvimento humano e o compromisso social, aperfeiçoa as decisões e melhora a qualidade dos serviços que a IES presta à sua clientela, a seu estado e ao país.

\section{Considerações finais}

A auto-avaliação de Centros de PósGraduação vem ganhando importância, de forma crescente, na medida em que se intensificam as discussões em torno da busca por maior qualidade e eficiência das organizações de educação superior. Daí a implantação desse processo avaliativo, de forma democrática, como primeira experiência coletiva, contando com a participação dos vários segmentos - professores, funcionários e alunos - do Centro de PósGraduação e Pesquisa Visconde de Cairu, porque eles conhecem bem a realidade institucional e, com segurança, são os mais interessados em melhorá-la. 
A auto-avaliação foi realizada através da metodologia da pesquisa-ação, em forma de oficinas vivenciais, e a partir de três momentos chaves: no primeiro momento, a comunidade acadêmica descreveu, com relação ao Centro de Pós-Graduação, os sentimentos que facilitam e dificultam o desenvolvimento de suas atividades profissionais/acadêmicas; no segundo, construiu uma visão diagnóstica do Centro de PósGraduação e dos vários setores. Num clima de discussão e diálogo, as explicações e interpretações do que ocorria no dia-adia de cada segmento foram sendo apontadas e digitadas nos Quadros 1, 2 e 3, disponibilizados nos computadores. Neles puderam identificar os pontos positivos, que deveriam ser estimulados, e as distorções e soluções convenientes para os problemas encontrados. Também realizaram a metaavaliação. No momento 3, fizeram a integração das auto-avaliações desenvolvidas individualmente e/ou em pequenos grupos.

Cabe destacar que a participação e envolvimento dos vários segmentos da comunidade acadêmica, apesar da pequena representatividade das categorias aluno e professor em um dos Programas, permitiram que a reflexão e análise apresentadas fossem amadurecidas e coerentes com o contexto educativo. Conhecendo-se a si mesmo, através do processo de auto-avaliação permanente, o CEPPEV pode, de forma dinâmica, ir aperfeiçoando suas com- petências institucionais e acadêmicas.

A partir daí, percebe-se que a avaliação e a gestão organizacional devem estar articuladas, servindo como instrumento de mudança e correção de rumos, e vinculadas ao processo de tomada de decisões. A proposta de ação organizada em quadros pela comunidade acadêmica trouxe, de forma coerente, equilibrada e exeqüível, alternativas que vão facilitar aos gestores, na implementação de estratégias de intervenção, para corrigir rumos, consolidar ou superar sua ação pedagógica e alcançar, efetivamente, maior qualidade institucional.

Constata-se, enfim, que o processo de auto-avaliação do CEPPEV está apenas começando, e deve ser contínuo e permanente, para a construção da cultura da avaliação, que os resultados parciais apresentados, de forma coletiva e cooperativa, podem estimular a comunidade acadêmica a novas reflexões e debates que conduzam ao descobrimento de outras dimensões da realidade e outras necessidades.

Espera-se que a auto-avaliação do Centro de Pós-Graduação e Pesquisa Visconde de Cairu (CEPPEV), pensada aqui como espaço democrático, continue mantendo a crítica construtiva como mecanismo orientador da prática cotidiana de seus participantes, professores, funcionários, alunos e gestores. 


\section{Referências}

BELLONI, I. A função social da avaliação institucional. In: DIAS SOBRINHO, J.; RISTOFF, D. I. (Org.). Universidade desconstruída. Florianópolis: Insular, 2000. p. 37-58.

BRASIL. Decreto No 3.860, de 9 de julho de 2001. Dispõe sobre a organização do ensino superior, a avaliação de cursos e instituições, e dá outras providências. Diário Oficial [da] República Federativa do Brasil, Brasília, DF, 2001. Disponível em: $<$ http://portal.mec.gov.br/sesu/arquivos/pdf/DecN3860.pdf>. Acesso em: 20 maio 2005.

BRASIL. Lei n 9.394, de 20 de dezembro de 1996. Estabelece as diretrizes e bases da educação nacional. Diário Oficial [da] República Federativa do Brasil, Brasília, DF, 23 dez. 1996. Disponível em:< http://portal.mec.gov.br/arquivos/pdf/ldb.pdf $>$. Acesso em: 13 abr. 2005.

BRASIL. Ministério da Educação. Secretaria de Educação Superior (SESU). Plano Nacional de Extensão, 1999-2002. Brasília, DF, 1999. Disponível em:

$<$ http://portal.mec.gov.br/sesu/index. php? option=content\&task=view\&id $=440>$.

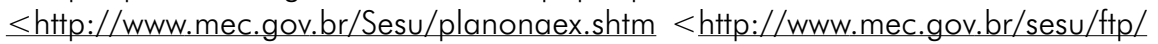
extens. $\mathrm{nf}>$. Acesso em: 18 maio 2005, 13 dez. 2006.

CENTRO DE PÓS-GRADUAÇÃO E PESQUISA VISCONDE DE CAIRU. Roteiro de autoavaliação. Salvador, 2004.

CRONBACH, L. J. Course improvement through evaluation. Teachers College Record, New York, v. 64, n. 8, p. 672-683, May 1963.

DIAS SOBRINHO, J.; RISTOFF, D. (Org.). Universidade desconstruída. Florianópolis: Insular, 2000.

FÓRUM NACIONAL DE PRÓ-REITORES DE EXTENSÃO DAS UNIVERSIDADES PÚBLICAS BRASILEIRAS, 1., 1999, Brasília. Sistema de dados e informações e RENEX (Rede Nacional de Extensão). Brasília, DF, 1999. Disponível em: <http://www.ufmg.br/ proex/renex/arquivos/gt_siex_relatorio_final.doc.> Acesso em: 20 maio 2005.

GUBA, E.; LINCOLN, Y. Fourth generation evaluation. Newbury Park: Sage, 1990.

HOFFMANN, J. Avaliação: mito e desafio: uma perspectiva construtivista. Porto Alegre: Educação \& Realidade, 1993.

MASETTO, M. Auto-avaliação em cursos de Pós-Graduação: teoria e prática. São Paulo: Papirus, 2004. 
SCRIVEN, M. The methodology of evaluation. In: TYLER, R. W. et al. Perspectives of curriculum evaluation. Chicago: Rand McNally, 1967. (AERA Monograph series on curriculum evaluation, n.1).

SORDI, M. R. Entendendo as lógicas da avaliação institucional para dar sentido ao contexto interpretativo. In: VILLAS BOAS, B. M. F. (Org.). Avaliação: políticas e práticas. Campinas, SP: Unicamp, 2002.

STUFFLEBEAM, D. L. et al. Educational evaluation and decision making. Itasca: Peacock, 1981.

Recebido: 28/06/2006

Aceito para publicação: 10/07/2006 